\title{
Attitudes of mental health vs. non-mental professionals towards patients presenting with attempted suicide: a comparative study
}

\author{
Mona Srivastava, Ranjana Tiwari
}

\section{Background}

Suicide is a major public health problem. Clinicians attitudes can influence proper management and follow-up of patients who are at risk of repeated self harm.

Aims

This study attempts to compare the attitudes of mental health and non-mental health workers towards patients who attempt suicide.

\section{Methods}

We used an attitude questionnaire, used previously in India, which looked at attitudes of emergency room clinicians towards attempted suicide. The self administered questionnaire had 34 items with yes/no responses. The study sample included a group of 30 non mental health clinicians working in an emergency department. The comparison group consisted of a convenience sample of 30 mental health professionals. We carried out an exploratory factor analysis and identified six factors which described the data. The mean factor scores of the two groups were compared

\section{Results}

The mental health professionals had significantly higher scores for factors 1,4 and 5 which indicate a positive attitude of mental health professionals towards dealing with the patients who have attempted suicide, compared to non mental health professionals.

\section{Conclusions}

Training and education of non-mental health professionals must be encouraged to change their attitude towards patients who attempt suicide and this will help in the better management of these patients.

SL J Psychiatry 2011; 2 (2):63-66

\section{Introduction}

Suicide is a major public health problem as recognised by the World Health Organization $(1,2)$. In the United States of America, suicide is the eleventh leading cause of death in adults, fourth leading cause of death in children, thirs leading cause of death in young people aged 15 to 24 years and accounts for 30,000 deaths annually $(3,4)$. Individuals who survive an act of attempted suicide are at a higher risk of reattempting using a highly lethal method. (5).

Clinical decision making is influenced by a complex interactions between the patient and clinicians as well as socio-cultural and contextual factors (6). The management of a patient attempting suicide should be based on theoretical knowledge and empirical data but unfortunately research shows that "unrelated" factors can also affect the clinician's judgement. Some of these are a patient's attractiveness, socio-economic status and the clinician's own values. (6). These factors can interfere in the proper management and follow-up of patients who are at risk of repeated self harm and the attitudes of clinicians often can interfere with prevention strategies (5). Non mental health professionals come into frequent contact with individuals who are at high risk of self harm and therefore play an important role in the prevention of suicide (7). A recent study has shown that non-mental health professionals form an important link in the management and prevention of suicide (3). Liaison between mental and non-mental health professionals can help reduce rates of suicide (8).

A study of attitudes of mental health and non-mental health workers towards patients who attempt suicide will help identify any negative attitudes and this can subsequently help plan training and education. Studies examining this issue are limited in number in India therefore we decided to study this important area.

\section{Methods}

\section{Study design}

A cross sectional study was carried out at a nodal multi-speciality tertiary care hospital. The hospital is a central government run hospital situated in Varanasi, Uttar Pradesh, India which caters to a large population of patients and serves as an important treatment centre with a vast catchment area. The study sample included a group of 30 non mental health professionals from the general medicine, surgery, neurology, anaesthesia, neurosurgery, and orthopaedics and gynaecology and obstetrics departments, serving in the Departments of Emergency Medicine. Since the Department of Emergency Medicine is the first point of contact for a patient who attempts suicide, we chose trainee residents who are posted to the department on a rotational basis or are called to attend to the emergency referrals. All the trainee residents posted to the Emergency Medicine Department, during the study period, who consented to participate in the study were included in the non mental health group. The comparison group consisted of a convenience sample of 30 mental health professionals consisting of psychiatrists, psychologist, psychiatric social workers and psychiatric nurses. The study was approved by the ethical committee of the hospital. 
Table 1 -Comparison of mean scores between groups

\begin{tabular}{|c|c|c|c|}
\hline Mean & $\begin{array}{l}\text { Non-mental } \\
\text { health } \\
\text { professionals } \\
\text { mean (SD) }\end{array}$ & $\begin{array}{l}\text { Mental } \\
\text { health } \\
\text { professionals } \\
\text { mean (SD) }\end{array}$ & $\begin{array}{l}\text { Significance } \\
P\end{array}$ \\
\hline Factor 1 & $3.78 \pm 1.05$ & $5.42 \pm 1.57$ & $\begin{array}{l}t=5.20 \\
p<0.001\end{array}$ \\
\hline Factor 2 & $3.19 \pm 3.75$ & $4.00 \pm 2.37$ & $\begin{array}{l}t=1.86 \\
p=0.67\end{array}$ \\
\hline Factor 3 & $3.14 \pm 1.55$ & $3.25 \pm 4.81$ & $\begin{array}{l}t=1.83, \\
p=0.72\end{array}$ \\
\hline Factor 4 & $2.42 \pm 1.03$ & $3.25 \pm 1.48$ & $\begin{array}{l}t=2.78 \\
p=0.007\end{array}$ \\
\hline Factor 5 & $2.42 \pm 0.97$ & $2.72 \pm 1.00$ & $\begin{array}{l}t=2.39, \\
p=0.02\end{array}$ \\
\hline Factor 6 & $1.72 \pm 2.11$ & $0.88 \pm 0.95$ & $\begin{array}{l}t=-1.80 \\
p=0.076\end{array}$ \\
\hline
\end{tabular}

We used an attitude questionnaire, used in another study in India which looked at attitudes of emergency room clinicians towards suicide (9). The questionnaire was found to have good reliability. This self administered questionnaire had 34 items with yes/no responses. Some sample questions in the questionnaire were: do you volunteer to care for patients who have attempted suicide?, do you think suicide is an act of courage?, Do you think suicide is an act of cowardice?, do you think suicide is an act of manipulation?, do you think patients attempting suicide need love and attention?, does talking about suicide increase the risk of suicide?, does attempting suicide indicate the presence of a mental illness, does dealing with patients who attempt suicide irritate you?, does talking about suicide make you anxious? and do you think treating patients who attempt suicide place an unnecessary burden on the doctor?

The questionnaire was administered to the respondents after obtaining written informed consent. The identity of the respondents was kept confidential. The questionnaire was collected from the respondents after one day. The responses were analysed by grouping the responses under six factors.

\section{Data analysis}

The data was analysed using SPSS- version 13 for Windows. The original study described eight factors which best described the attitude of clinicians. We carried out an exploratory factor analysis and identified six factors which described the data. The mean factor scores of the two groups were compared. The factors were grouped as 'positive' if they conveyed attributes like empathy, concern, understanding, open mindedness, acceptance, and helpful behaviour. The 'negative' attitudes were the ones which conveyed

\begin{tabular}{l}
$\begin{array}{l}\text { Table 2- Correlation between factors -non-mental health } \\
\text { professional }\end{array}$ \\
\hline
\end{tabular}

hatred, anger, indifference and manipulativeness. The six factors identified were factor I -acceptance; factor II-understanding; factor III-helpful behaviour; factor IV-manipulativeness (considers act of suicide as manipulative); factor V-indifference; factor VIrejection (attitudes of rejection of towards patient). The factors were named based on the predominant attitude conveyed by the responses to the questions.

\section{Results}

There were 30 respondents from each group. The mental health group consisted of psychiatrists $(n=8)$, psychologists $(\mathrm{n}=14)$, psychiatric social workers $(n=6)$ and psychiatric nurses $(n=2)$. The non-mental health group comprised of those from the department of general medicine $(n=18)$ and the rest were from surgery $(n=4)$, neurology $(n=6)$ and gynaecology and obstetrics $(n=2)$. Table 1 shows the comparison of the mean factor scores between the two groups using the t test. The non-mental health group had significantly lower scores for factors 1,4 and 5. Attitudes such as empathy, understanding, and helping behaviour towards the patients were significantly less in the non mental health group.

Table 2 shows the correlation matrix for the six factors in the non-mental health group, There was significant negative correlation between factors 1 and 5 and positive correlation between factors 1 and 6.Table 3 shows the correlation matrix for of the six factors among mental health professionals.

\section{Discussion}

Our findings are similar to those of a previous study carried out in India (9). A comparison of attitudes between the two groups revealed that the mental health clinician group had significantly higher scores on factors 1,4 and 5 as listed in the results. This indicated that the mental health professionals had more positive attitudes towards patients presenting after attempted suicide while the non-mental health professionals had a relatively less engaging attitude towards them.

Mental health clinicians deals with people undergoing stress and difficulties hence they may be more adept at addressing and discussing such issues and their training may also help them develop more positive attitudes. These clinicians are better at dealing with issues of helplessness, despair and non-adjustment in patients. Non-mental health professionals may not have been trained to consider aspects other than
Table 3- Correlation between factors -mental health professional

\begin{tabular}{|c|c|c|c|c|c|c|}
\hline & $\mathrm{F} 1$ & $\mathrm{~F} 2$ & $\mathrm{~F} 3$ & $\mathrm{~F} 4$ & F 5 & $\mathrm{~F} 6$ \\
\hline Factor 1 & 1 & $.48^{* *}$ & $.77^{* *}$ & $.60^{* *}$ & $.35 * *$ & $.48^{* *}$ \\
\hline Factor 2 & & 1 & .306 & .628 & .11 & .36 \\
\hline Factor 3 & & & 1 & $.57^{* *}$ & $.39 * *$ & $.48^{* *}$ \\
\hline Factor 4 & & & & 1 & $.39 *$ & $.53^{* *}$ \\
\hline Factor 5 & & & & & 1 & .333 \\
\hline Factor 6 & & & & & & 1 \\
\hline
\end{tabular}


a "biological model" of illness. They may be less considerate of the patient's emotional state. The work pressure and their own anxieties in dealing with such patients can also influence their attitudes. Another issue of relevance is the medico legal aspect, because managing a patient after attempted suicide becomes tedious and complicated due to its legal implications and the procedures involved $(9,10)$.

The appropriate management of patients who attempt suicide is important as this group is vulnerable and is at risk of re-attempting which could result in a completed suicide $(10,11)$. In India, organophosphates are among the commonest methods used to attempt suicide because of their easy availability. Patients who use organophosphates are first managed in emergency departments (12). The clinicians in emergency departments who are responsible for the management of these patients have to be trained adequately, to bring about a positive change in their perceptions regarding suicide, mental wellbeing and patients with psychiatric illness. The Emergency Department is the first point of contact and is often the gateway to mental health professionals $(10,13,14)$.

Asia contributes a majority (61\%) of all suicides world wide (2). This alarming figure is partly because of poor access to mental health facilities and partly due to various other socio-familial and cultural factors (16). Among family physicians, lack of knowledge and anxiety about how to handle suicidality contribute to how they deal with such patients (17). If the process of committing suicide is considered as a continuum, then it begins as an ideation, continues with planning, preparing and ends with threatening and the eventual suicide attempt. This continuum can be interrupted at multiple points and the act may be prevented (18, 24). Suicidal individuals frequently approach nonmental health professionals in the period between contemplation and completion which can last as long as one year (18). Men and older people are known to frequently contact services during the contemplation period (18).

Mental health professionals namely doctors trained in psychiatry, psychologists, psychiatric nurses, social workers and special educators are better equipped to assess and manage suicidal patients. Attitudes of nonmental health professionals may be influenced by education and training. Such training can contribute to reducing the risk of subsequent suicide attempts $(16,19-22)$. A study done by Beautrais showed that a positive change in attitudes occurred after training programmes (23).

Our study also found that medico-legal issues influence attitudes. Unnecessary paper work and subsequent legal procedures have a negative impact on the attitudes of non-mental health professionals. This is an important issue that needs to be addressed (9). Because medicolegal issues have already been dealt with when mental health professionals assess the patient, medico-legal issues have less of an impact on them.
Crisis intervention teams in emergency departments could also reduce the burden on emergency room clinicians, which can result in more positive attitudes towards patients who attempt suicide (11).For patients at high risk of self harm the crisis intervention team can also serve as a link to community services (19).

Our study had important limitations. The tool used had 'yes' and 'no' answers. This could be improved by an instrument which uses a Likert scale of scoring. The sample was small; hence the applicability of the data maybe limited. We would propose that a study be carried out on a larger population, where training of non-mental health professionals in dealing with patients attempting suicide maybe undertaken and a pre and post-training assessment of attitudes could be performed.

Despite these limitations, our study suggests that suicidal patients-who form a special subset of all emergency referrals-may be helped by attitudinal changes among clinicians which can lead to better interactions with patients, proper referral and immediate crisis intervention by an expert team which in turn may lead to a decline of re-attempts of the act (1).

\section{Acknowledgement}

We wish to acknowledge all those who participated in the study

\section{Declaration of interest \\ None}

\section{Mona Srivastava,}

Assistant Professor, Department of Psychiatry, Institute of Medical Science, Banaras Hindu University, Varanasi-221005, (U.P), India

\section{Ranjana Tiwari,}

Research scholar, Department of Psychiatry, Institute of Medical Science, Banaras Hindu University, Varanasi-221005, (U.P), India.

\section{Corresponding author}

Mona Srivastava, Assistant Professor, Department of Psychiatry, Institute of Medical Science, Banaras Hindu University,Varanasi-221005, (U.P), India

E mail: drmonasrivastava@gmail.com

\section{References}

1. Suicide Statistics in http://www.suicide.org/suicide. html, accessed on Feb.2010.

2. Vijay Kumar L. Suicide and mental disorders in Asia. Int Rev Psychiatry 2005; 17(2):109-114. Suicide Statistics in http://www.suicide.org/suicide.html, accessed on Feb.2010.

3. Baraff LJ, Janowicz N,Asarnow JR. Survey of California emergency departments about practices for management of suicidal patients and resources available for their care. Ann Emerg Med 2006; 48(4): 452-58. CrossRef

4. Institute Of Medicine. Reducing Suicide: A national imperative. Washington. D.C, National Academy Press; 2002 Available at: http://www.iom.edu/ CMS/3775/3838/3843.aspx. 
5. Stewart SE, Manion IG, Davidson S, et al. Suicidal children and adolescents with first emergency room presentations: Predictors of six months outcome. J Am Acad Child Adolesc Psychiatry 2001; 40(5): 580- 87. CrossRef

6. Dressler SM, Prusoff B, Mark H, Shapiro D. Clinicians' attitude towards the suicide attempter. J Nerv Ment Dis 1975; 160:146- 55. CrossRef

7. Gutherie E, Kapur N, Mackway-Jones K, et al. Randomised controlled trail of brief psychological intervention after deliberate self poisoning. BMJ 2001; 323:135-38. CrossRef

8. Kapur N, Cooper J, Hiroeh U, et al. Emergency department management and outcome for self poisoning: A cohort study. Gen Hosp Psychiatry 2004; 26(1):36-41. CrossRef

9. Sethi S, Upaal S. Attitude of clinicians in emergency room towards suicide. Int J Psychiatry Clin Pract. 2006; 10(3):182-85. CrossRef

10. Buzan RD, Weissberg MP. Suicide: risk factor and therapeutic considerations in emergency department. J Emerg Med 1992; 10:335- 43. CrossRef

11. Brown GK, Tenhlave T, Henriagnes GR, et al. Cognitive therapy for the prevention of suicide attempts: A randomised controlled trial. JAMA 2005; 294:563-70. CrossRef

12. Latha KS, Bhat SM, Souza P. Suicide attempters in general hospital unit in India; Their sociodemographic and clinical profile: Emphasis on cross cultural aspects. Acta Psychiatr Scand 1996; 94(1): 26-30. CrossRef

13. Goldestien RB, Black DW, Nasrallah A, et al. The prediction of suicide: Sensivity, specificity, and predictive value of a multivariate model applied to suicide among 1906 patients with affective disorders. Arch Gen Psychiatry 1991; 48: 418- 22. CrossRef

14. Pokomy AD. Prediction of suicide in psychiatric patients: report of a prospective study. Arch Gen Psychiatry 1983; 40(3): 249-57. CrossRef

15. Doshi A, Bourdeanux ED, Wang N, et al. National study of US emergency department visits for attempted suicide and self- inflicted injury 1997-2001. Ann Emerg Med 2005; 46: 369-75. CrossRef

16. Repper J. A review of the literature on the prevention of suicide through interventions in accident and emergency departments. J Clin Nurs 1999; 8(1): 3-12. CrossRef

17. Stoppe, Sanhoze H, Huppertz C, et al. Family physicians and risk of suicide in depressed elderly. J Affect Disord 1999; 54:193-98. CrossRef

18. Hsin-Chien Lee, Herng-Ching Lin, Tsai-Ching Liu, Shiyng-Yu Lin. Contact of mental and non-mental health care providers prior to suicide in Taiwan- A population based study. Can J Psychiatry 2008; 53(6):377-83.

19. Gutstein SE, Rudd MD. An outpatient treatment alternative for suicidal youth. J Adolesc 1990; 13: 26577. CrossRef

20. Dennis M, Beach M, Evans PA, et al. An examination of the accident and emergency of deliberate self-harm J Accid Emerg Med 1997; 14: 311-15. CrossRef

21. Spirito A, Boergers J, Donaldson D. Adolescent suicide attempters: Post attempt course and implications for treatment. Clin Psychol Psychother 2000; 7(3):161-73. CrossRef

22. Brunero S , Smith J , Bates E , Frairbrother G. Health professionals attitude towards suicide prevention initiativesJ Psychiatr Ment Health Nurs 2008; 15:58894. CrossRef
23. Beautrais AL. Risk factors for suicide and attempted suicide among young people. Aust N Z J Psychiatry 2000; 34(3): 420-36. CrossRef

24. Jeglic EL, Will my patient attempt suicide again? Curr Psychiatr 2008; 7(11): 19-28 